\title{
Evaluation of P/M Ring Gear Using Computed Tomography and Ultrasonic Testing
}

\author{
J. J. Haskins, P. Martin
}

February 22, 2001

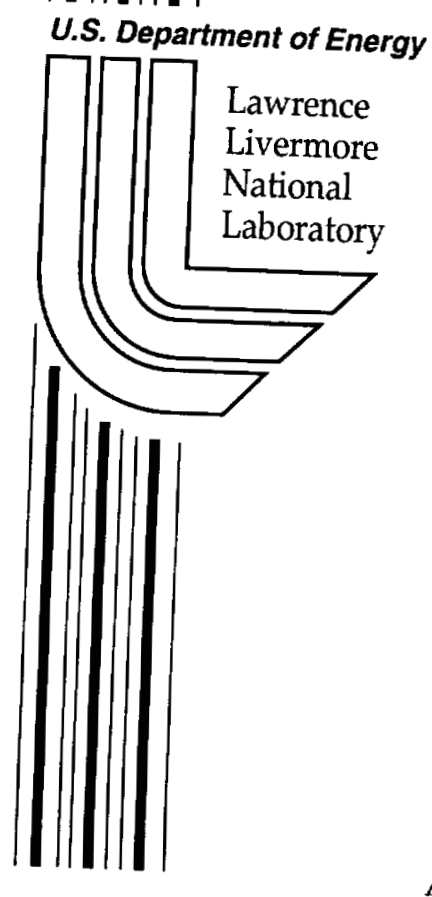




\section{DISCLAIMER}

This document was prepared as an account of work sponsored by an agency of the United States Government. Neither the United States Government nor the University of California nor any of their employees, makes any warranty, express or implied, or assumes any legal liability or responsibility for the accuracy, completeness, or usefulness of any information, apparatus, product, or process disclosed, or represents that its use would not infringe privately owned rights. Reference herein to any specific commercial product, process, or service by trade name, trademark, manufacturer, or otherwise, does not necessarily constitute or imply its endorsement, recommendation, or favoring by the United States Government or the University of California. The views and opinions of authors expressed herein do not necessarily state or reflect those of the United States Government or the University of California, and shall not be used for advertising or product endorsement purposes.

This work was performed under the auspices of the U. S. Department of Energy by the University of California, Lawrence Livermore National Laboratory under Contract No. W-7405-Eng-48.

This report has been reproduced directly from the best available copy.

Available electronically at http://www.doc.gov/bridge

Available for a processing fee to U.S. Department of Energy

And its contractors in paper from

U.S. Department of Energy

Office of Scientific and Technical Information P.O. Box 62

Oak Ridge, TN 37831-0062

Telephone: (865) 576-8401

Facsimile: (865) 576-5728

E-mail: reports@adonis.osti.gov

Available for the sale to the public from

U.S. Department of Commerce

National Technical Information Service

5285 Port Royal Road

Springfield, VA 22161

Telephone: (800) 553-6847

Facsimile: (703) 605-6900

E-mail: orders@ntis.fedworld.gov

Online ordering: http://www.ntis.gov/ordering.htm

OR

Lawrence Livermore National Laboratory

Technical Information Department's Digital Library

http://www.llnl.gov/tid/Library.html 


\title{
EVALUATION OF P/M RING GEAR USING COMPUTED TOMOGRAPHY AND ULTRASONIC TESTING
}

\author{
Jerry J. Haskins \\ Peter Martin \\ NDE Section \\ Lawrence Livermore National Laboratory \\ Livermore, California
}

Ultrasonic (UT) and computed tomography (CT) evaluation of a P/M ring gear was performed at LLNL to characterize the gear and to determine the relative sensitivity of the two techniques to defects of interest. The photograph and sketch shown below show the geometric complexity of the gear.

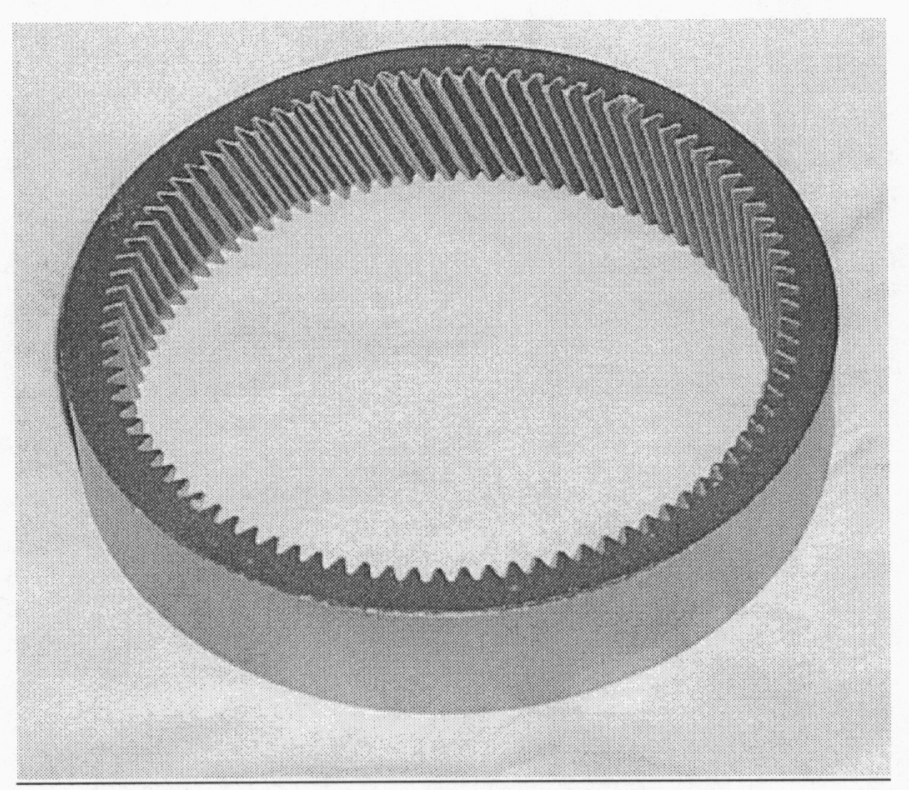

Figure 1: Photograph of Ring Gear.

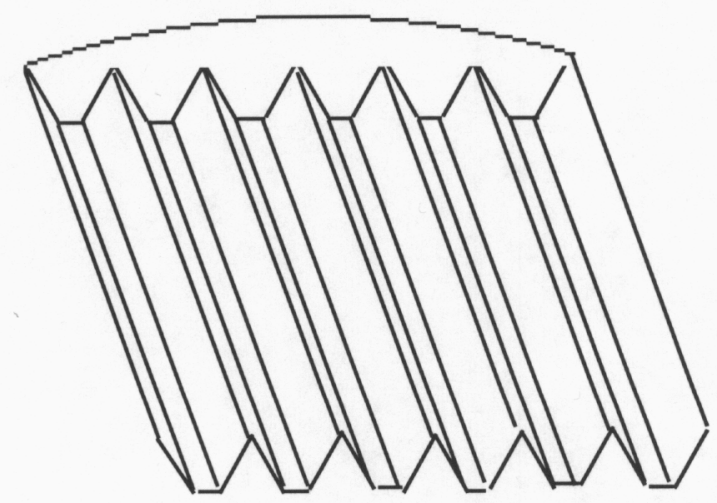

Figure 2: Sketch of Ring Gear Tooth Profile. 
The features of concern lie at the root of the teeth and in layers along the sides of the teeth. These layers can be detected using metalography but success depends on chance and the number of sections polished. Much of the current focus is on improving the sensitivity of the CT scan and on better ways to evaluate the large data sets obtained. The initial data obtained showed anomalies close to the gear teeth as expected. Later data showed anomalies at other locations and in other orientations. Figure 3 below shows a radiograph with vertical and horizontal CT slices through regions with anomalies.

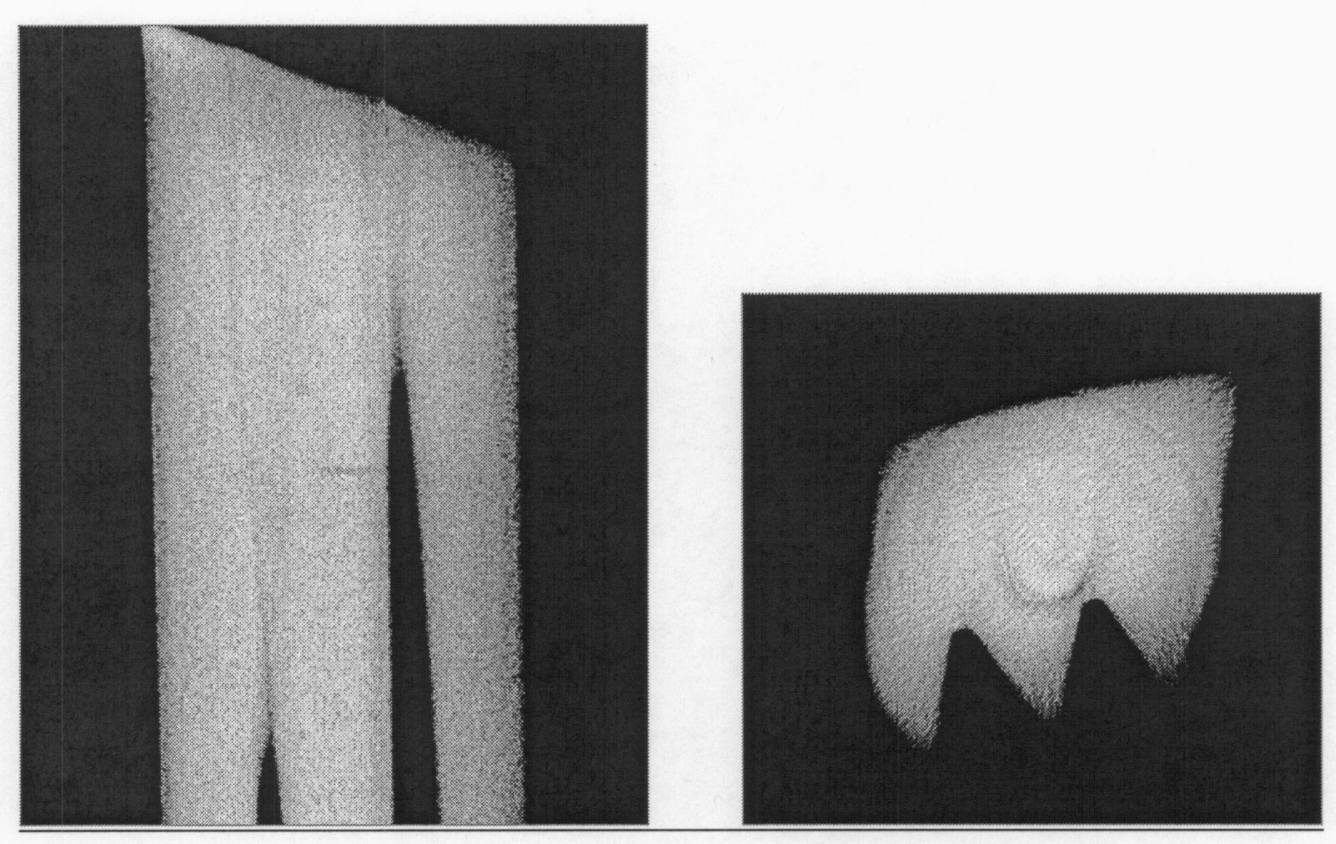

Figure 3: $\mathrm{Y}$ and $\mathrm{Z}$ slices through ring gear sample show large anomaly near root of tooth.

\section{Ultrasonic Testing (UT) Of Pressed, Sintered Powder Specimens}

UT inspection was performed on a complete gear to locate regions of interest for further study and for correlation with other data generated. The measurements were configured in such a fashion that the sound waves were focussed to the base of the gear teeth (the bottom of the notches). This was done because the principal defects of interest are discontinuities related to low powder packing density in that vicinity. Data from a C-scan is shown in Figure 4. The data are useful for locating discontinuities buried in a large volume, however care must be taken in interpretation due to the color-amplitude correlation. The signal amplitude can be significantly affected by changes in surface quality and/or orientation. Given that the ring gears in question were significantly out-of-round, and also had some surface curvature in the axial direction it is difficult to correlate amplitude measured at different locations without optimizing the alignment at each location. 


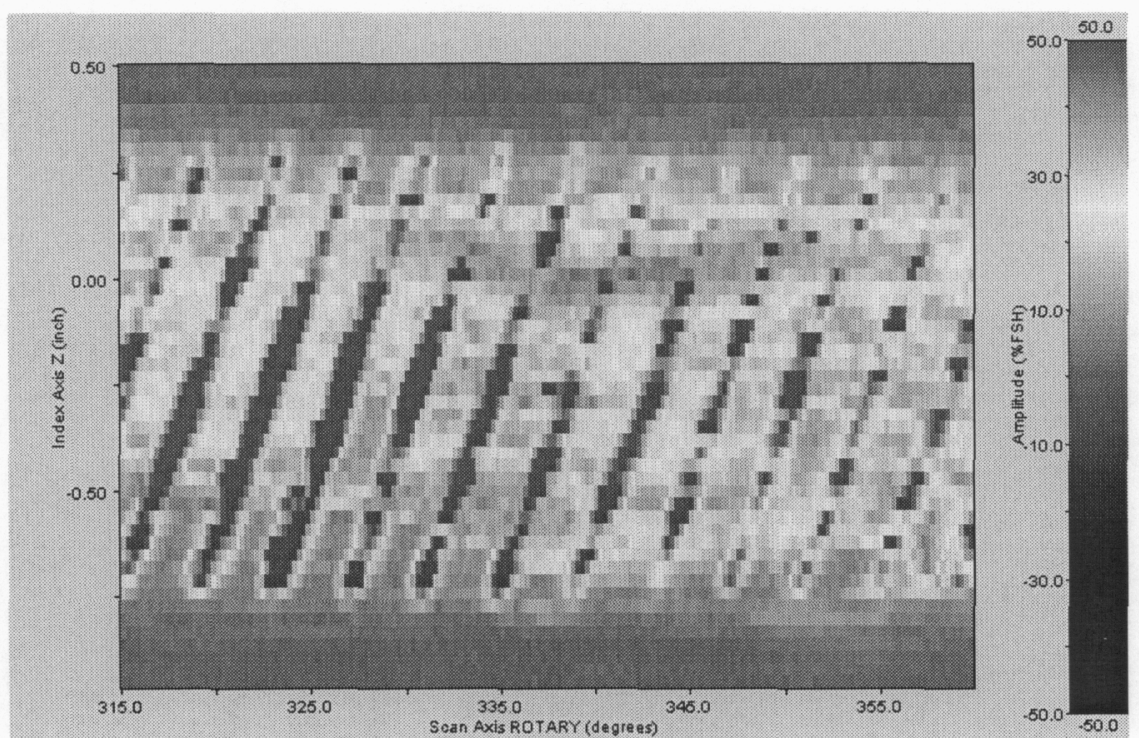

Figure 4: C-scan image of a $45^{\circ}$ section of a ring gear. Color is proportional to signal amplitude. The gate is set to interrogate $6 \mathrm{~mm}$ below the base of the gear teeth.

The observed discontinuity return in the B-scan in Figure 5 is a clear indication of a significant discontinuity in the part. The location of the discontinuity is slightly over $1 \mathrm{~mm}$ below the base of the teeth. It should be noted that these types of discontinuity were observed at various depths in the component, even near the surface. However, for the purpose of the current study, the defects of primary interest are in the region around the base of the teeth since this is the most problematic location in terms of potential gear (tooth) failure.

Note the 'wavy' front running across the image in Figure 5 at approximately $30.50-30.75 \mu \mathrm{s}$. This artifact corresponds to a spurious (multiple path) echo from the front face of the specimen. Thus, while the location of the echo does not correlate to any physical feature of the component at the corresponding depth in the material, the shape (i.e. 'waviness') corresponds to the degree of roundness of the outside circumference of the part. The waviness in the figure corresponds to approximately $0.5 \mathrm{~mm}$ of surface displacement. Note that the gear tooth echoes follow the surface displacement, so the indication is not of varying thickness but rather of constant thickness and an out-of-round condition.

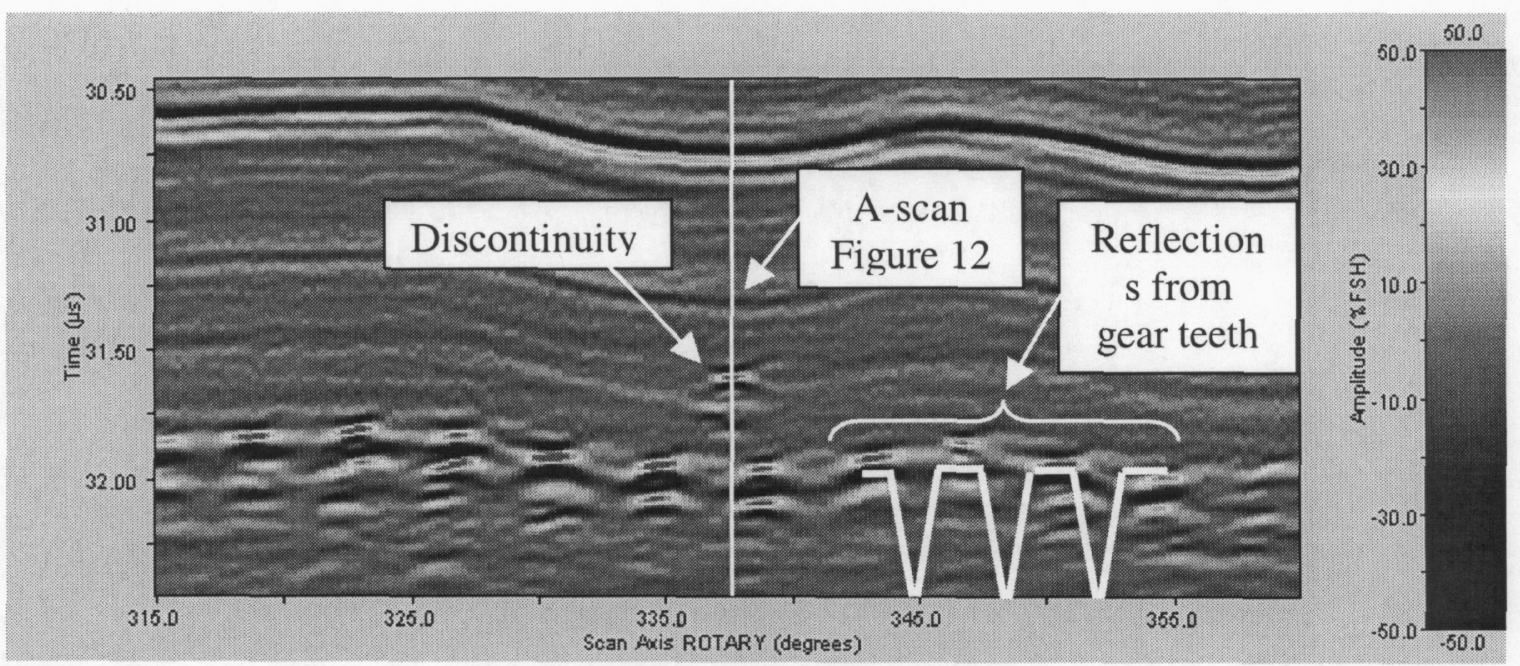

Figure 5: B-scan showing time of flight of the acoustic signal versus degrees around the ring gear (from $315-360^{\circ}$ ). Color is proportional to signal ampuitude. Note the discontinuity return at $\sim 338^{\circ}$. The gear 
teeth are indicated schematically, and the vertical white line indicates the location of the A-scan shown in Figure 12.

Analysis of the C-scan data shows that the approximate dimensions of the discontinuity are 0.05 " in the $\mathrm{z}$-axis and $1.5^{\circ}$ around the circumference. Given the location of the discontinuity, this corresponds to a circumferential dimension of approximately 0.07 ". It should be noted that this calculation should, to be precise, account for other factors such as beam diffraction and spot size

\section{Conclusions From Study}

The following conclusions can be drawn from the data acquired during the testing of the ring gears:

- There are discontinuities present in the component.

- $\quad$ These discontinuities can be located and sized using UT and CT testing.

- The discontinuities do not appear to occur at any characteristic depth or location.

In order to build upon these results, and to enhance the capabilities for inspection of powder metallurgical components, the following action items are proposed for continuation of the research efforts:

- $\quad$ Regions of the ring gear containing discontinuities will be sectioned.

- $\quad$ These sections will be inspected using CT.

- $\quad$ Some discontinuity-free regions of the ring gear will be used to fabricate calibration standards (with flat bottomed holes).

- $\quad$ The UT and CT data will be compared, potentially complementary capabilities will be identified.

- $\quad$ Selected areas will be evaluated metalographically 